\title{
Management and Control Systems for Large Scale Integration of Renewable Energy Sources into the Electrical Networks
}

\author{
F. O. Resende, J. A. Peças Lopes, Senior Member, IEEE
}

\begin{abstract}
This paper presents a general overview about the system operation, management and control following a large scale integration of renewable energy sources, focusing in particular the wind generation, both onshore and offshore. Regarding the operation of distribution networks, the integration of renewable energy sources and other distributed generation systems requires the adoption of active control and management structures. These structures will contribute to extend intelligence from the transmission to the distribution networks, aiming to change the operation paradigm from passive towards the smart grids vision for European networks of energy. The MicroGrid concept plays a key role in this context and has been exploited in order to support the progressive integration of electric vehicles, trying to avoid grid reinforcements.
\end{abstract}

Index Terms-Renewable energy sources, integration of wind generation, grid management and control, grid codes, virtual power plant, micro grids, smart grids.

\section{INTRODUCTION}

Energy supply in Europe has been dominated by the large scale centralized combustion of fossil fuels (coal, oil and gas), nuclear and hydro power, with energy delivered over long distances to consumers. Concerning the Europe sustainable development, this traditional economy of scale presents some drawbacks. On the one hand, a significant amount of Europe's generation capacity, both coal and nuclear fuelled, is reaching the end of its useful life and the network infrastructure is also old, requiring investments in a short-term on the transmission and distribution systems. On the other hand, the continuous increasing demand for energy, in particular for electricity, has stressed a number of shortcomings:

- High level of dependency of imported fuels leading to potential price rises and potential supply disruptions;

- Large environmental impact on greenhouse gases and other pollutants;

- Increased transmission losses;

- Necessity for continuous upgrading of transmission and distribution systems.

Whilst energy remains a major component of economic

The authors are with INESC-Porto (Institute of Engineering and Computer Systems of Porto), Rua Dr. Roberto Frias, 378, 4200-465, Porto, Portugal. J. A. Peças Lopes is also with FEUP (Faculty of Engineering of Porto University), Porto, Portugal (e-mail: fresende@inescporto.pt; ipl@,fe.up.pt). growth, such deficiencies have a direct impact on the world economical development, stability concerning the security of energy supply, environmental protection and well-being of world's citizens. These issues provided the main drivers for power systems development within the framework of EU sustainability.

Wind generation systems, both onshore and offshore, as well as solar systems, both thermal and photovoltaic, - just to mention a few - are new forms of electricity generation that have been developed. They define the so called Renewable Energy Sources (RES) and involve the exploitation of distributed sources through the concept of Distributed Generation (DG). Today, large and small hydro power systems are stabilized technologies and onshore wind power technologies are entering into a competitive level with traditional forms of energy generation. In the near future it is expected that one speaks also about offshore wind and wave energy systems, solar power plants and microgeneration systems involving microturbines, photovoltaic systems and fuel cells, etc.

RES and DG for heating, cooling and electricity have the potential to become the foundation of a future more sustainable energy supply system. Their large scale deployment will transform the energy landscape from a system dominated by the centralized combustion of fossil fuels to a new one in which new technologies, environmentally friendly, contribute to a substantial development. On the other hand, DG can offer additional value to the grid system operators by providing [1]:

- Deferral of investments to transmission and distribution systems;

- Reduction of losses in the distribution system;

- Provision of network ancillary services.

From an investment view point, it is generally easier to find sites for RES and DG than for large central power plants and, in addition, such units can be installed in a short time, near to the end consumer. The widespread integration of RES and DG together with energy efficiency, covering supply and demand, have provided support to achieve the major EU policy objectives by 2020 [2], [3]:

- Sustainable development, combating climate changes and reducing air pollutants. The shift from the large scale combustion of fossil fuels to a more decentralized energy supply based on RES has contributed for 
meeting the Kyoto commitments, regarding the emission of greenhouse gases in $20 \%$ compared to 1990;

- Raising the share of renewable energy to $20 \%$;

- Improve energy efficiency by $20 \%$;

- Security and diversity of energy supply, since reducing the external energy dependence is crucial for the development of a dynamic and sustainable economy for Europe;

- Energy market liberalization, increasing opportunities for smaller scale generators.

However, the integration of both RES and DG into the overall power systems operation requires that energy generation in both transmission and distribution systems can no longer be considered as a passive appendage. Reliability, safety and quality of power are the main issues linked to the large-scale deployment of DER so that their effect on the European transmission and distribution networks cannot be neglected. Rather, it must be addressed with a comprehensive system approach [3]. Issues related with system active management and control are becoming more and more important within the framework of how to increase the penetration levels of DER exploiting benefits for system operation ensuring, at the same time, future power supply reliability and quality.

\section{MAIN ISSUES WHEN INTEGRATING LARGE AMOUNTS OF WIND POWER IN THE ELECTRICAL SYSTEM}

Large scale integration of both onshore and offshore wind raises challenges for the various stakeholders, involving generation, transmission, distribution, power trading and consumers. Thus, in order to integrate wind power successfully, a number of issues have to be addressed in the following areas [4]:

- System operation, involving reserves capacities and balancing management, short term forecasting of wind power and cross border flow management;

- Grid connection of wind power and system transient stability (grid codes and power quality, wind turbine technologies and control issues);

- Grid infrastructure issues comprising congestion management, extension and reinforcements, specific issues of offshore wind generation and interconnection;

- Contribution of wind power to system adequacy (on generation, energy source and transmission levels);

- Market redesign issues to facilitate wind power integration (demand side management, storage, balance settlement rules, time between schedule and delivery at the balance market);

- Institutional issues, involving mainly vertical integration, legal and ownership unbundling, incentives of stakeholders, non-discriminatory third-party grid access and socialization of costs.

Some of these areas are addressed in a more detailed way in the following sections.

\section{OPERATING POWER SYSTEMS WITH WIND POWER INTEGRATION}

Concepts of grid connected Wind Turbine Generation Systems (WTGS) have been evolved in the last decades to MW size power generation units with advanced control systems based on both blade pitch systems and on the variable speed feature, exploiting the control flexibility provided by the power electronic interfaces. Therefore, WTGS can be controlled actively, meaning that the power output is not only determined by the incoming wind speed but also based on system requirements. Nowadays, the WTGS technological developments enable wind farms to be operated according to the Virtual Power Plant (VPP) concept, thus providing system ancillary services [4]. Then, wind farms have the ability to contribute for improving system stability, fault recovery and system voltage support. Whereas not necessary at low penetration levels, these advanced control functionalities have proven to be increasingly useful at high levels of wind power integration.

\section{A. Increasing system operation flexibility}

The availability of balancing solutions in power systems, including generation capabilities, load management and energy storage systems, constitutes a key issue that contributes to increase the integration levels of wind power in power systems. Existing balancing solutions involve mostly conventional generation units equipped with synchronous machines such as hydro-power and pumped hydro as well as thermal power plants.

Hydro-power is commonly regarded as a very fast way to reduce power imbalance due to its fast ramp-up and rampdown rates. Also, it has a marginal cost close to zero, making it a very competitive solution. Furthermore, pumped hydro allows energy storage during valley hours when there are surplus of wind generation and electricity is cheap in order to face the demand during peak hours when prices are higher. In turn, thermal units are commonly used for power system balancing as well, providing primary and secondary frequency control. Of these, gas fired units are often considered to be most flexible allowing a fast adjustment of generation to demand. System operators have to match supply to demand over a wide range of time periods, being this task associated with specific forms of generation, storage and load control.

\section{1) Energy storage systems}

The range of technologies for dedicated storage is potentially wide [5]. However, pumped hydro power installation is the most common and best known technology. Other technologies include compressed air, flywheels, batteries, fuel cells and supercapacitors. There is increasing interest in both large scale dedicated storage affecting transmission network and in smaller scale dedicated storage embedded in distribution networks.

\section{2) Demand side management}

With Demand Side Management (DSM) loads are influenced to respond to power imbalances by reducing or increasing power demand. Part of the power demand can be 
time shifted or simply either switched off/on according to price signals. This allows a new balance between generation and consumption without having to adjust generation levels. DSM is much less commonly applied today than adjusting generation levels. The availability of this solution depends on load management possibilities and also on the economic benefits resulting from the flexible load contracts [6].

\section{B. Wind power cluster management}

Operating wind farms as VPP can bring advantages from the system view point since wind farms can generate power and also provide system ancillary services. The concept of cluster management, also called wind generation dispatch centers, will include the aggregation of geographically dispersed wind farms according to various criteria, aiming the purpose of an optimized network management and also an optimized generation schedule [7]. Since $100 \%$ accuracy of wind power production forecasting is not achievable, the difference between the forecast and actual supply must be minimized by means of control strategies of wind farm cluster management to ensure the generation schedule. In this case, the power output will be controlled according to the schedule determined by the short-term forecasting. Time variable setpoints should be constantly generated and refreshed for an optimum interaction between wind farms and the corresponding cluster management systems. For the purposes of this kind of operation management, it is assumed a continually updated short-term forecasting for wind farms and cluster regions, exploiting global numerical weather prediction results that are afterwards combined with online data, using mesoscale and physical models together with statistical adaptive tools [8]. Non-controllable wind farms can be supported by controllable ones in a particular cluster. This strategy will allow the contribution of clusters of wind farms to fulfill system requirements, including mainly [4]:

- Congestion levels management in case of the amount of wind power generation allow exceeding the maximum thermal ratings of grid components. These situations can be foreseen and avoided by network simulations based on wind generation forecasting and by the limitation of the wind power output to a predefined threshold. Different wind farms in a cluster can be curtailed differently, giving thus an opportunity for an economical optimization of the process.

- Loss reduction and optimization of both active and reactive power flows. Wind power generation is variable, not only in time domain, but also geographically and, therefore, these variations can lead to power flows over large distances with associated losses. Such situations can be identified beforehand and reduced or even prevented by the interaction of wind farm clusters with conventional power plants. The transmission of reactive power can be managed in a similar way.

Having in mind that wind farms can be connected at both the transmission and distribution systems, a dialogue between the wind power cluster management system and both TSO and DSO is required, as well as with the market operator. The specific nature of the installed WTGS usually requires specific applications to be installed at the wind park management system level. Such applications should be able to dispatch active and reactive generations when set points are sent to the individual wind park management systems by grid operators. The operation of the wind power cluster management systems requires also the availability of several managing tools, being the wind generation forecasting tools the most relevant ones.

When hydro-pumping storage is available, new functionalities able to identify the best combined wind-hydro pumping storage strategies should be used. For that purpose, wind power forecasts are also needed together with the electricity price behavior forecasts. The identification of optimized daily operation strategy can be determined by solving an optimization problem where the economic benefits of such strategy are driving an objective function [9].

\section{GRID CONNECTION REQUIREMENTS OF WTGS: GRID CODES}

As already mentioned previously, early wind power generation was injected in distribution networks, but, in recent years, more and larger wind farms, both onshore and offshore, have been connected to transmission networks. Each of these network levels has specific requirements when integrating wind power generation, being the network connection issues mainly related to grid stability which is influenced by power flows and wind farms dynamic behavior in case of network faults. At high wind power integration levels, providing grid support becomes an important feature of wind farms.

Grid operators, both transmission and distribution, have developed grid codes for connecting WTGS and the wind turbine manufacturers have respond to these requirements by develop advanced functionalities in the field of WTGS control and electrical system design [10]. Essential grid code requirements are related to frequency, voltage and WTGS behavior following the occurrence of grid faults.

\section{A. Frequency control}

Several grid codes require the participation of wind farms in primary and secondary frequency control, including frequency response capability and limitation of both ramp rates and active power output. Regarding ramp rate limitations, some TSO require the limitation of positive and even negative changes of active power outputs to suppress large frequency variations. The requirements are expected to become stricter at higher wind power integration levels in order to avoid exceed power gradients of conventional power plants responsible for primary and secondary frequency control. Some operators also require that WTGS should stay connected and in operation at a wider frequency band in order to contribute to frequency restoration and stable power systems operation.

\section{B. Voltage control}

The basic grid codes requirements involve the continuous operation of WTGS in normal voltage ranges, maintaining the terminal voltage constant, and to stay connect during voltage 
step changes within the specified voltage ranges. Other requirements include reactive power capability and voltage control. Since conventional generation can be replaced by large wind farms, WTGS should be capable to supply reactive power dynamically in order to contribute to maintain the reactive power balance. Therefore, the individual WTGS have to control their own terminal voltage to a constant value by means of an automatic voltage regulator, allowing that modern wind farms have capability to control the voltage at the Point of Common Coupling (PCC) to a pre-defined set-point of grid voltage, as dispatched by the TSO. Expanded reactive power capabilities can bring advantages for system operators because it offers the possibility of better balancing the reactive power demand.

\section{Fault Ride-Through capability}

Following the increasing integration levels of wind generation Fault Ride-Through (FRT) and Low Voltage RideThrough (LVRT) capability has been the major concern of system operators, since large transient voltage depressions may propagate across wide network areas and the disconnection of wind farms under fault conditions can pose a serious threat to network security of supply because a large amount of wind generation could be lost simultaneously. Thus, WTGS must remain connected during and after severe grid disturbances, ensure fast restoration of active power to pre-fault levels as soon as the fault is cleared and inject reactive current in order to support the grid voltage during disturbances and to provide fast voltage recovery after fault clearing.

\section{Compliance with grid code requirements}

Different concepts of WTGS comply with grid code requirements in different ways. Fixed Speed Induction Generators (FSIG) directly connected to the grid are not capable to meet wider operational frequency ranges as required in several grid codes. However, the operation of modern WTGS in a wider frequency range is not a complicated task.

For any generator, the ability to control frequency requires control of a prime mover. Although the wind speed cannot be controlled, most of the modern WTGS can control the output power and therefore provide frequency control. For this purpose, pitch controlled wind turbines are set in advance at a level below the rated output, allowing them to provide primary and secondary frequency control.

The capability of WTGS to control voltage and reactive power depends also on the WTGS technology. FSIG is a consumer of reactive power and needs additional equipment to provide fast control of reactive power, such as Static Var Compensation (SVC) devices and STATic synchronous COMpensators (STATCOM). Also, FRT capability can be assisted by external static compensation devices usually connected at the PCC [11]. Also, it would be beneficial to install FACTS is several strategic buses in order to mitigate the impact of short-circuits taking place in the network [8]. Apart from avoiding the tripping of some generation units, a good damping of the oscillations can be obtained. Variable speed WTGS are capable of reactive power control in order to fulfill power factor requirements. Nowadays, most of the WTGS manufacturers offer FRT capability, allowing the WTGS to withstand a wider range of voltage variations, for longer periods, without disconnection, which considerably increases the stability margin [8], [12], [13].

\section{GRID INFRASTRUCTURE FOR LARGE SCALE INTEGRATION OF WIND GENERATION}

Market, technology and environment bring along several changes and challenges for European transmission networks that have been developed in the second half of the last century and confined to countries or network areas, being the interconnections used to increase reliability and to provide frequency support in case of contingencies within the UCTE system [4]. One of the major drivers is the emerging internal electricity market in Europe, requiring sufficient transport capabilities between regions to enable competition. Making the grid more suitable for increased transactional power flows can be seen as an opportunity to increase the wind power integration levels into the European power systems [14]. Furthermore, the specific nature of distributed and variable output generation requires the development and implementation of new technology and grid management concepts, as already mentioned previously.

The adaptation of the transmission network is a complex process subjected to a strategic long term planning, involving mainly the optimal use of the transmission networks with wind power in a short-term and, in a mid and long term, the creation of the Trans European Transmission Networks and Europe wide offshore grids [14].

According to [15], wind power integration applies to the following main improvements:

- High voltage transmission links between countries;

- Offshore transmission links interconnecting different offshore wind farm areas and load centers over long distances.

This second category has received increasing attention with increasing distance of wind farms from the shore.

\section{A. European super grids for offshore wind power}

The transportation of large amounts of power from large offshore wind farms to load centers all over Europe will require the development of Europe wide offshore grids and trans-European overlay grids [15]. The proposed scenarios require high investments in the grid infrastructure. However, they constitute the most promising long term options for an energy economy based on RES with a large share of wind generation.

Compared to onshore, offshore wind farms will have large power capacities with sizes comparable with conventional power plants. Therefore, transmission technologies operating at high voltage levels will be required to transmit the generated power over long distances [10]. Recent advances in High Voltage Direct Current (HVDC) technology using IGBT 
based power electronic converters constitutes a promising solution to facilitate the cost effective construction of multiterminal HVDC networks. These modern systems offer technological advantages, especially in the area of controllability and efficiency. The reactive power control capability is an important advantage of HVDC systems favoring grid integration and system stability [16]. The technical and economical aspects of offshore transmission systems are being actively investigated by the supply industry and by electric power companies in order to be ready with the most cost effective solutions when large scale offshore wind power takes off [10].

\section{B. The TWENTIES Project: Provision of system ancillary services by multi-terminal HVDC offshore networks}

The TWENTIES project aims at demonstrating by early 2014 through real life, large scale demonstrations, the benefits and impacts of several critical technologies required to improve the pan-European transmission network, thus giving Europe a capacity of responding to the increasing share of renewable in its energy mix by 2020 and beyond while keeping its present level of reliability performance [17].

In contrast with AC networks, power flows inside the DC grid result directly from the control actions of the power converter stations. This coordinated management and control is also the key issue that will allow the multi-terminal HVDC offshore networks to assure robustness of operation when facing internal disturbances and, simultaneously, to provide system ancillary services [18].

The coordinated control and management system of the HVDC multi-terminal offshore networks will be addressed taking into account the following aspects:

- Control of multiple DC/AC power electronic converters as injectors in the onshore networks;

- Commercial exchanges and contribution to the European electricity market;

- Congestion management on the onshore AC networks by proper coordination actions on the DC/AC power stations;

- Losses management;

- Increasing robustness of HVDC based multi-terminal offshore networks

- Capability of providing system ancillary services.

Regarding the multi-terminal HVDC offshore networks operation under the framework of the VPP concept, the system ancillary services that have been addressed comprise mainly: Frequency control, voltage support and contribution for the damping of system oscillations. A brief overview of these subjects is presented in the following sections:

1) Frequency control

In $\mathrm{AC}$ grids, system frequency deviation is a general indicator of unbalance between load and generation and therefore it makes possible to design quite expedite control loops for power/frequency control. Regarding offshore HVDC grids, specific control algorithms should be identified to detect frequency deviations taking place in $\mathrm{AC}$ onshore networks into the HVDC offshore network. Regarding the response of the DC/AC power electronic converters, primary frequency control can be envisaged as a supplementary inertia control loop to be included in offshore WTGS control systems in order to exploit the kinetic energy stored in the rotating masses of wind turbines and power exchanges/support with AC neighboring systems by exploiting the HVDC offshore network.

\section{2) Voltage support and FRT capability}

In normal operating conditions voltage control will be assured by the DC/AC power electronic converters.

Following a system disturbance, such as a short circuit taking place in AC transmission onshore networks, the response of the WTGS connected to AC networks, during the fault and after its clearance by the appropriate switchgear, depends on their technologies, as already mentioned previously. In case of HVDC offshore networks, the identification and development of innovative technological solutions is required in order to ensure FRT capability requirements in case of balance and unbalanced faults through the injection of reactive current into the $\mathrm{AC}$ onshore network by $\mathrm{DC} / \mathrm{AC}$ power electronic converters. Regarding unbalanced faults, innovative control techniques should be developed aiming the injection of different amounts of reactive current in each phase of the system in order to avoid over-voltages in the non-faulted phases.

\section{3) Contribution for the damping of system oscillations}

Following the large scale integration wind generation it is also necessary to guarantee that problems of small signal stability do not arise [19]. The most frequent cause of this kind of instability is the lack of damping of the so-called electromechanical modes of oscillation. Reduction of damping can arise from situations where the connection of wind power in one area of the grid replacing conventional generation located in another area, increases the power flows through weak interconnection lines. This situation may occur in the future, for example, in the north of Europe with the integration of large offshore wind farms.

Power System Stabilizers (PSS) installed in the excitation systems of synchronous generators is still one of the most cost effective solutions capable of providing supplementary damping. However, in a system with a large share of wind generation these devices may no longer be able to provide the necessary additional damping. Therefore, it will be necessary to implement damping functions in the HVDC grid control system.

\section{THE MICROGRID CONCEPT: ENABLING THE SMARTGRIDS VISION AND PROVIDING SUPPORT TO THE MOBILITY PARADIGM}

Large deployment of small generation units with power ratings less than a few tens of kilowatts to Low Voltage (LV) networks has lead with the development of the MicroGrid (MG) concept [20], as a new paradigm for the development of electric power system enabling the smartgrids vision. Microgeneration can offer substantial environmental benefits through the integration of RES, such as wind and solar. Also, 
the connection of microgeneration systems brings significant benefits for power system operation in terms of loss reduction and reliability improvement. Future grid reinforcement and expansion can also be deferred since branch congestions can be controlled. Furthermore, the MG hierarchical control and management system supported by a communication infrastructure allows the $\mathrm{MG}$ operation as an extremely flexible cell of the electrical power system, which can be operated in two different modes:

- Normal interconnected mode, when the $\mathrm{MG}$ is connected to the MV network, being either partially supplied from it or injecting some power to it.

- Emergency mode, when the MG is operated autonomously, as in physical islands, following a disconnection from the upstream MV network.

Reduction of LV consumer's interruption time can be performed by allowing $\mathrm{MG}$ islanded operation, until MV network is available, and by exploiting MG local generation and control capabilities to provide fast black start at the LV level. Storage devices play a key role in assuring the MG operation in islanded mode [21].

The progressive integration of Electric Vehicles (EV) poses new challenges regarding the technical operation of electric networks, namely in LV networks as a result of the presence of individual points both domestic or public for slower charging. The technical management of power systems having a large deployment of $\mathrm{EV}$ will require for their battery charging a combination of [22]:

- A centralized hierarchical management and control structure;

- A local control located at the EV grid interface level.

In fact, the simple use of smart EV grid interfacing devices does not solve all the problems arising from $\mathrm{EV}$ integration in distribution LV networks. These interfaces can be rather effective when dealing with voltage drops arising from EV charging, by locally decreasing charging rates through a voltage droop control approach, but fail when addressing issues that require a higher control level, such as managing the branches congestion levels. For this purpose, a coordinated control is required and so a hierarchical control and management structure responsible for the entire grid operation, including EV management through the implementation of smart charging strategies, should be available. In this context the MG concept has been exploited to support the progressive integration of EV trying to avoid grid reinforcements. Also, the presence of distributed storage provided by the EV batteries when connected to the LV networks can be exploited in order to help managing the system operation, in particular the MG islanded operation.

\section{CONCLUSIONS}

The effective integration of large shares of RES requires a set of new technical solutions and operational rules where information and communication technologies will play a key role. These solutions involve mainly, a wise level of central management and decision regarding network reinforcements and operation planning, cooperation among all the power system players and the definition of new technical requirements for robust and safe system operation. This will contribute to increase society benefits related to energy policies.

\section{REFERENCES}

[1] N. Jenkins, R. Allan, P. Crossley, D. Kirschen, G. Strbac, Embedded Generation. London, United Kingdom: IEE Power and Energy Series 31, 2000.

[2] An Energy Policy for Europe: Communication from the Commission to the European Council and the European Parliament, ec.europa.eu/energy/energy_policy/doc/01_energy_policy_for_europe_en .pdf 2007.

[3] M. Sánchez-Jiménez, "Smart Electricity Networks: European drivers and projects for the integration of RES and DG into the electricity grids of the future," presented at 3rd European Conference PV-Hybrid and Mini-Grid, Aix en Provence, France, 2006.

[4] Large scale integration of wind energy in the European power supply: analysis, issues and recommendations, $\mathrm{A}$ report by EWEA, http://www.wind-energy.de/fileadmin/dokumente/Themen_AZ/Netzausbau/EWEA_Grid_report_europe.pdf.

[5] Paulo F. Ribeiro, Brian K. Johnson, Mariesa L. Crow, Aysen Arsoy, Yilu Liu, Energy storage systems for advanced power applications, Proceedings of the IEEE, vol. 89, August 2002.

[6] P. Djapic, C. Ramsey, D. Pudjanto, G. Strbac, J. Mutale, N. Jenkins, R. Allan, Taking an active approach, IEEE Power\&Energy Magazine, 2007.

[7] R. G. Almeida, E. D. Castronuovo, J. A. Peças Lopes, Optimum generation control in wind parks when carrying out system operator requests, IEEE Transactions on Power Systems, vol. 21, nº 2, June, 2006.

[8] A. Estanqueiro, Rui Castro, Pedro Flores, João Ricardo, Medeiros Pinto, Reis Rodrigues, J. Peças Lopes, How to prepare a power system for $15 \%$ wind energy penetration: The portuguese case study, Wind Energy, 2007.

[9] P. Brawn, J. A. Peças Lopes, M. A. Matos, Optimization of pumped storage capacity in na isolated power system with large renewable penetration, IEEE Transactions on Power Systems, vol. 22, $\mathrm{n}^{\circ}$. 2, July 2008.

[10] T. Ackermann, Wind power in power systems, Wiley \& Sons, 2005.

[11] F. O. Resende, J. A. Peças Lopes, Evaluating the performance of fault ride-through solutions used in wind farms with fixed speed induction generators when facing unbalanced faults, IEEE Bucharest PowerTech, 2009.

[12] N. W. Miller, E. V. Larsen, J. M. MacDowell, Advanced control of wind turbine generators to improve power system dynamic performance, $11^{\text {th }}$ International Conference on Harmonics and Quality of Power, September, 2004.

[13] S. Hartger, et al, Ride-through capability of ENERCON wind turbines, Proceedings Billund, 2003

[14] L. Meeus, K. Purchala, D. V. Hertem, R. Belmans, Regulated crossborder transmission investment in Europe, European Transactions on Electrical Power, vol. 16, May 2006.

[15] Concerted Action for Offshore Wind Energy Deployment, www.offshorewindenergy.org/cod/COD-Final_Rept.pdf.

[16] X. Chen, H. Sun, J. Wen, W. J. Lee, X. Yuan, N. Li, L. Yao, Integrating wind farm to the grid using hybrid multiterminal HVDC technology, IEEE Transactions on Industry Applications, vol. 47, December, 2010.

[17] TWENTIES Project, http://www.twenties-project.eu/node/1

[18] S. Henry, A. M. Denis, P. Panciatici, Feasibility study of offshore HVDC grids, IEEE Power and Energy Society General Meeting, July, 2010.

[19] A. Mendonça, J. A. Peças Lopes, Robust tuning of power system stabilizers to install in wind energy conversion systems, IET Renewable Power Generation, vol. 3, nº 4, 2009.

[20] J. A. Peças Lopes, C. L. Moreira, A. G. Madureira, Defining control strategies for microgrids islanded operation, IEEE Transactions on Power Systems, vol. 21, nº. 2, May 2006.

[21] C. L. Moreira, F. O. Resende, J. A. Peças Lopes, Using low voltage microgrids for service restoration, IEEE Transactions on Power Systems, vol. 22, no. 1, February, 2007.

[22] J. A. Peças Lopes, F. J. Soares, P. M. R. Almeida, Integration of electrical vehicles in the electric power system, Proceedings of the IEEE, vol. 99, $\mathrm{n}^{\mathrm{o}}$. 1, January 2011. 